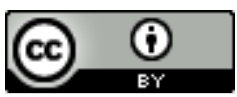

\title{
SOSIALISASI KEGIATAN KAWASAN KESELAMATAN OPERASI PENERBANGAN DI DINAS PERHUBUNGAN KABUPATEN TANGERANG
}

\author{
Taufik Rohman ${ }^{1}$, Hemi Pamuraharjo ${ }^{2}$, Solihin $^{3}$, Sundoro $^{4}$, Alwazir Abdusshomad $^{5}$ \\ 1) taufik.rohman@ppicurug.ac.id*, Politeknik Penerbangan Indonesia Curug, Tangerang \\ ${ }^{2)}$ hemi.pemurahardjo@ppicurug.ac.id, Politeknik Penerbangan Indonesia Curug, Tangerang \\ ${ }^{3)}$ solihin@ppicurug.ac.id, Politeknik Penerbangan Indonesia Curug, Tangerang \\ 4) sundoro@ppicurug.ac.id, Politeknik Penerbangan Indonesia Curug, Tangerang \\ 5) alwazir@ppicurug.ac.id, Politeknik Penerbangan Indonesia Curug, Tangerang \\ * untuk penulis korespondensi
}

\begin{abstract}
The role of The Indonesian Aviation Polytechnic as one of the campuses in the aviation world in curug area, Tangerang, Banten is considered necessary to carry out activities related to flight safety awareness through socialization activities of the Aviation Operations Safety Area (KKOP) for the community around the Airport area. Community Service Activities (PKM) is carried out at the Tangerang District Transportation Office and is expected to be able to provide information related to the world of aviation which includes land areas and / or waters and air space around the airport as flight operations to ensure flight safety. The activity is carried out for 1 day and uses the lecture method. In addition, cadets from the Diploma III Airport Operations Study Program are actively involved in the implementation of the program, with a view that cadets can communicate the knowledge they gain on campus directly to the surrounding community. The Tangerang District Transportation Office, where KKOP socialization activities take place, is expected to become more aware of the activities that occur in and around the flight operations area.
\end{abstract}

Keywords : KKOP, socialization, airport, flight

\begin{abstract}
Abstrak
Peran Politeknik Penerbangan Indonesia sebagai salah satu kampus di dunia penerbangan di wilayah Curug, Tangerang, Banten dipandang perlu melakukan kegiatan terkait dengan kewaspadaan keselamatan penerbangan melalui kegiatan sosialisasi Kawasan Keselamatan Operasi Penerbangan (KKOP) bagi masyarakat di sekitar area bandar udara. Kegiatan Pengabdian Kepada Masyarakat (PKM) ini dilaksanakan di Dinas Perhubungan Kabupaten Tangerang dan diharapkan mampu memberikan informasi terkait dunia penerbangan yang meliputi wilayah darat dan/atau perairan dan ruang udara di sekitar bandara sebagai operasional penerbangan guna menjamin keselamatan penerbangan. Kegiatan dilakukan selama satu hari dan menggunakan metode ceramah. Selain itu, taruna dari Program Studi Operasi Bandara Diploma III secara aktif terlibat dalam pelaksanaan program, dengan maksud agar para taruna dapat mengkomunikasikan pengetahuan yang mereka peroleh di kampus langsung kepada masyarakat sekitar. Kantor Dinas Perhubungan Kabupaten Tangerang, tempat kegiatan sosialisasi KKOP berlangsung, diharapkan menjadi lebih sadar akan kegiatan yang terjadi di dalam dan sekitar area operasi kegiata penerbangan.
\end{abstract}

Kata Kunci : KKOP, sosialiasi, bandara, penerbangan

\section{PENDAHULUAN}

Kawasan Keselamatan Operasi Penerbangan (KKOP) adalah wilayah di sekitar bandar udara yang digunakan untuk penyelenggaraan penerbangan yang meliputi darat, perairan serta ruang udara dalam rangka menjamin keselamatan penerbangan (Direktorat Jenderal Perhubungan Udara, 2015, 2016; Kementerian Perhubungan Republik Indonesia, 2015; Menteri Perhubungan Republik Indonesia, 2015; Presiden Republik Indonesia, 2009). Dampak dari ketidakpedulian masyarakat terhadap KKOP ini menyebabkan kewaspadaan terhadap keselamatan penerbangan menjadi meningkat. Perihal inilah yang mendorong Politeknik Penerbangan Indonesia Curug melalui program pengabdian kepada masyarakat memandang perlu melakukan sosialisasi terkait KKOP. Pandemi yang terjadi selama kurun waktu dua tahun sejak Maret 2020 berpengaruh sangat signifikan di bidang penerbangan (Vinod, 2021, N Kalbuana et al., 2021; Nawang Kalbuana, Asih, Putri, et al., 2021; Nawang Kalbuana, Asih, Simbolon, Solihin, \& Kurniawati, 2021). Hampir seluruh perekonomian didunia lumpuh (Arnas, Y; Lamtiar, S; Kurniawati, Z; Kurnianto, B; Kalbuana, 2021; Dewi, Yani, Yohana, Kalbuana, \& Tho'in, 2021; Hastomo, Karno, Kalbuana, Nisfiani, \& ETP, 2021; Hendriarto, 
Mursidi, Kalbuana, Aini, \& Aslan, 2021; Jatmoko et al., 2022; Kalbuana, N; Christelia, S; Kurnianto, B; Purwanti, T; Tho'in, 2021; Kalbuana, Nawang; Budi R, A.Nugroho; Yulistiani, 2020; Nawang Kalbuana, Sutadipraja, Purwanti, \& Santoso, 2019; Nawang Kalbuana, Utami, \& Pratama, 2020; Nurwati, Prastio, \& Kalbuana, 2021; Prasetyo, B; Utami, S; Abdusshomad, A; Wijaya, M; Kalbuana, 2021; Yohana; Kalbuana, N; Solihin; Yanti, 2020; Yohana, Gaol, Dewi, Kalbuana, \& Abdusshomad, 2021)

Sosialisasi kepada masyarakat melalui dinas perhubungan merupakan salah satu upaya memberikan pemahaman kepada masyarakat tentang kawasan keselamatan operasional penerbangan dengan segala aturan yang harus dipahamai dan dipatuhi serta berbagai dampak yang mungkin terjadi yang dapat merugikan keselamatan dan kerugian semua pihak, baik nyawa manusia maupun berupa harta dan juga berdampak pada hukum yang berlaku.

Kegiatan Pengabdian Kepada Masyarakat melakui kegiatan sosialisasi ini, diharapkan bagi para peserta mengetahui bahwa keselamatan adalah prioritas utama dan harus disediakan dalam setiap aktivitas penerbangan. Pengabdian kepada masyarakat adalah kegiatan civitas akademika yang memanfaatkan ilmu pengetahuan dan teknologi untuk memajukan kesejahteraan masyarakat dan mencerdaskan kehidupan bangsa. Pengabdian masyarakat merupakan suatu media yang menghubungkan dunia pendidikan dengan masyarakat sekitar (Arnas et al., 2021; Arti, Praptiningsih, P, \& Sadiatmi, 2020; Haris, Rosmayanti, Darjono, Purwaningtyas, \& Sugih, 2021; Jatmoko et al., 2022; Nawang Kalbuana, Hendra, et al., 2021; Prasetyo, Rohman, Solihin, Sundoro, \& Kalbuana, 2021; Sihono, Fatkhulloh, Saputro, Herwanto, \& Kalbuana, 2021; Sihono, Fatkulloh, et al., 2021; Toni, Wildan, Purnomo, Wahyudi, \& Fatra, 2022).

\section{METODE}

Kegiatan pengabdian kepada masyarakat yang dilaksanakan oleh para dosen PPI Curug yang memiliki latar belakang kompetensi bidang manajemen penerbangan, diselenggarakan secara tatap muka di Dinas Perhubungan Kabupaten Tangerang dengan tetap mengedepankan protokol kesehatan yang berlaku di masa pandemi Covid-19. Tahapan pelaksanaannya adalah sebagai berikut:

Tahap pertama merupakan tahap persiapan. Pada tahap ini kelompok pengabdi (PKM) melakukan penjajakan kerjasama pendahuluan untuk melihat kondisi di lapangan mengenai KKOP wilayah dengan pihak Dinas Perhubungan Kabupaten Tangerang yang masih merupakan area kawasan Keselamatan Penerbangan. Dalam tahap ini dicari permasalahanpermasalahan yang dihadapi oleh Masyarakat yang termasuk pada kawasan terkait KKOP.

Tahap Kedua selanjutnya merupakan tahapan pelaksanaan kegiatan pengabdian. Dalam tahap ini pengabdi melakukan kegiatan PKM sosialisasi KKOP, wilayah Dalam pengawasan Dinas Perhubungan Kabupaten Tangerang.

Tahap Ketiga yang terakhir adalah tahap evaluasi berupa tanya jawab perihal KKOP. Pada tahap ini dilakukan evaluasi atas hasil yang telah dicapai oleh peserta sosialisasi. Masukan dan perbaikan lebih lanjut dapat dilakukan pada tahap ini. Evaluasi diberikan dengan mengumpulkan data yang diperoleh dari kegiatan sosialisasi. Data diambil dengan menyimpulkan pemahaman apa yang narasuber sampaikan ketika diberikan pemaparan tayangan slide perihal KKOP, yang disampaikan dengan metode ceramah dan dilanjutkan dengan tanya jawab/diskusi. Indikator ketercapaian tujuan pengabdian adalah bahwa 80\% peserta sudah memahami KKOP, arti penting KKOP, arti penting peningkatan kualitas dan kuantitas pemahaman KKOP, sedang indikator ketercapaian untuk tujuan memberi bekal kemampuan masyarakat dalam mengembangkan dan pemahaman pengertian tentang KKOP dengan berbagai permasalahannya. 


\section{PENGMASKU}

Volume 1 No. 1, 2022

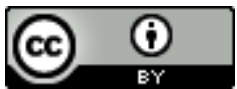

\section{HASIL DAN PEMBAHASAN}

Kegiatan PKM ini dilaksanakan pada hari Selasa tanggak 19 Oktober 2021. Kegiatan diawali dengan sambutan pertama oleh Direktur PPI Curug Bapak. Asri Santosa, S.T., S.Si.T., M.T. pada pukul 08.40, yang dilanjutkan dengan sambutan Kepala Dinas Perhubungan Kabupaten Tangerang.

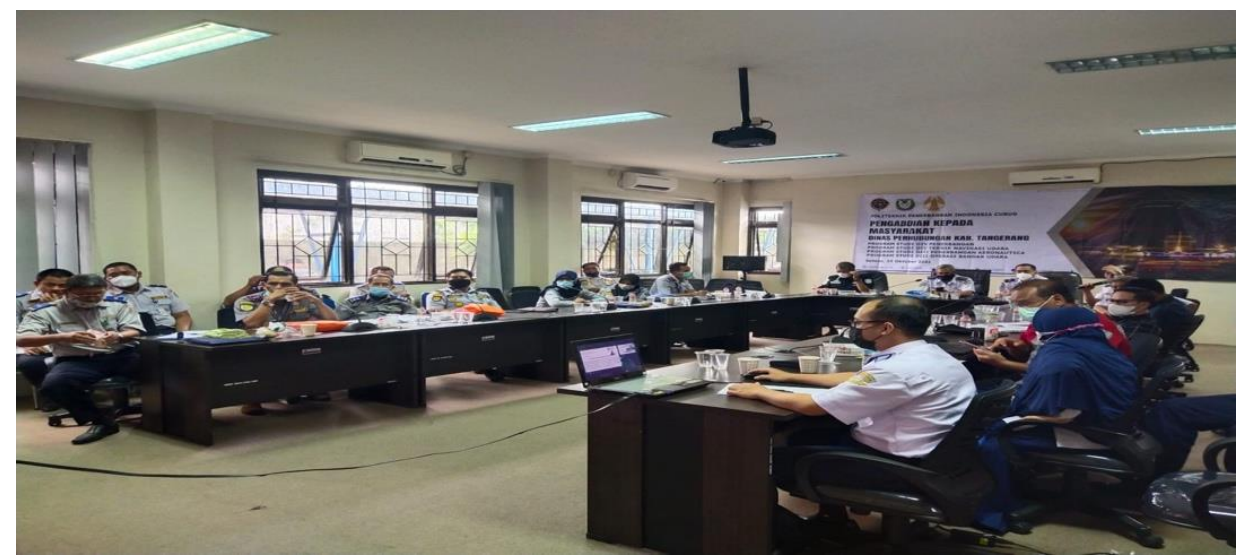

Gambar 1

Acara Pembukaan PKM

Setelah acara pembukaan, kegiatan PKM ini dilanjutkan dengan Sosialisasi tentang Kawasan Keselamatan Operasi Penerbangan oleh Bapak Hemi Pamuraharjo, S.H., DESS yang juga perwakilan dari anggota PKM yang sekaligus sebagai Ketua Program Studi D.III Operasi Bandar Udara di Politeknik Penerbangan Indonesia Curug.

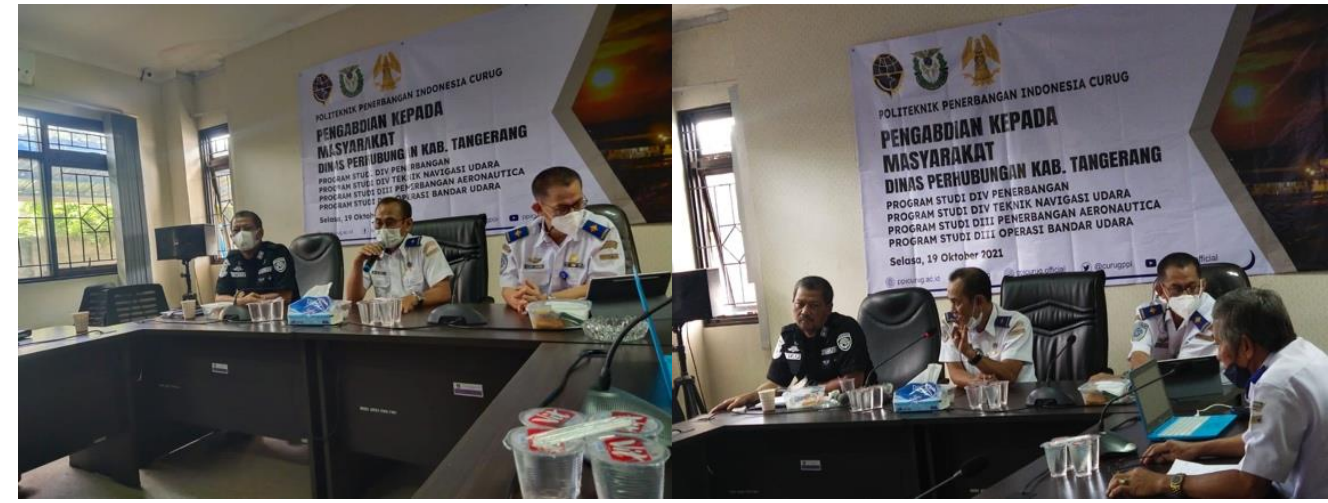

Gambar 2

Kegiatan Sosialisasi KKOP

Antusias dari peserta cukup tinggi hal tersebut dapat dilihat dari antusias para peserta terkait dengan kegiatan KKOP ini yang dilakukan pada sesi tanya jawab. 


\section{PENGMASKU}

Volume 1 No. 1, 2022
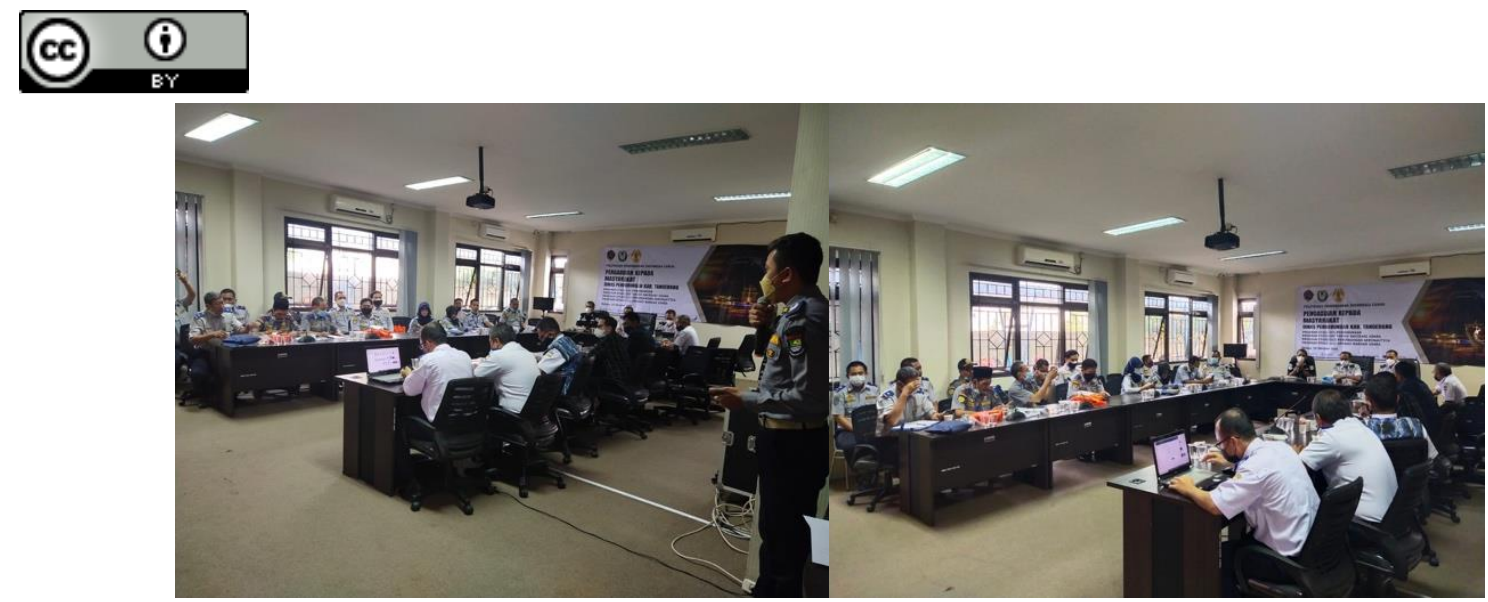

Gambar 3

Kegiatan Tanya Jawab Sosialisasi KKOP

Kegiatan sosialisasi KKOP ini secara resmi ditutup dengan doa yang dilanjutkan dengan pemberian cindera mata dan foto bersama peserta kegiatan pada pukul 15.30.
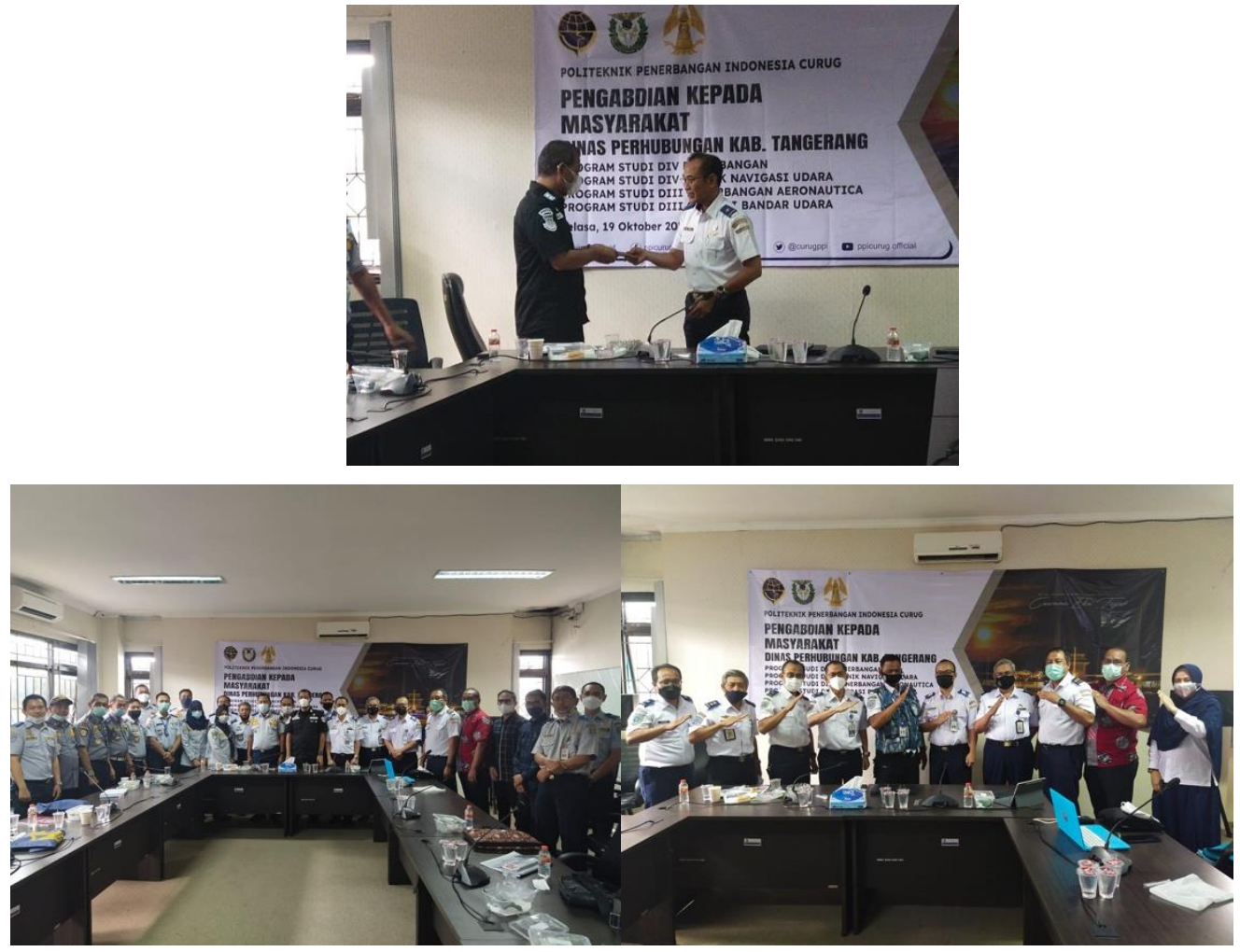

Gambar 4

Foto Bersama Peserta kegiatan Sosialisasi KKOP

\section{PENUTUP}

\section{Simpulan}

Sosilisasi KKOP yang diadakan di Dinas Perhubungan Kabupatan Tangerang pada tanggal 19 Oktober 2021 diperoleh hasil positif. Pendekatan secara persuasif dan edukatif yang dilakukan secara terus menerus diharapkan mampu memberikan pemahaman akan pentingnya kesadaran masyarakat demi menjamin keselamatan bersama. Sosialisasi dan pelatihanpelatihan diharap akan mampu menjawab permasalahan terkait dengan kondisi kemasyaraakatan yang tradisional kearah modern dengan modal pelatihan yang akan membekali mereka menjadi lebih mandiri. 


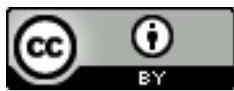

\section{Saran}

Diharapkan pada pengabdian kepada masyarakat berikutnya, Politeknik Penerbangan Indonesia Curug dapat memberikan edukasi lanjutan dan bersifat menyeluruh kepada masyarakat disekitar kawasan bandar udara sehingga diharapkan dengan adanya edukatif yang dilakukan secara terus menerus akan meningkatkan kesadaran masyarakat akan pentingnya kewaspadaan pada sisi wilayah udara di bandar udara.

\section{Penghargaan}

Penghargaan yang tinggi kami berikan kepada Kementerian Perhubungan RI, Badan Pengembangan SDM Perhubungan, Pusat Pengembangan SDM Perhubungan Udara dan khusus kepada Direktur Politeknik Penerbangan Indonesia Curug melalui Pusat Penelitian dan Pengabdian kepada Masyarakat atas dana hibah PKM yang diperoleh sehingga bisa menyelenggarakan kegiatan ini dengan normal dan tepat waktu.

\section{DAFTAR PUSTAKA}

Arnas, Y; Lamtiar, S; Kurniawati, Z; Kurnianto, B; Kalbuana, N. (2021). Factors Affecting Earning Management On Transportation Corporations In Indonesia. International Journal of Economics, Business and Accounting Research (IJEBAR), 5(1), 150-159. Diambil dari https://jurnal.stie-aas.ac.id/index.php/IJEBAR/article/view/2170/1012

Arnas, Y., Ismail, K. G. S. M., Kurniawati, Z., Kurnianto, B., Wibowo, I. H., \& Kalbuana, N. (2021). Pelatihan perawatan / service AC untuk masyarakat sekitar Politeknik Penerbangan Indonesia Curug. Penamas: Journal of Community Service, 1(2), 90-99.

Arti, E. S., Praptiningsih, N., P, R. A., \& Sadiatmi, R. (2020). Pengenalan Pelayanan Lalu Lintas Udara ( Air Trafic Service ) di Indonesia. Jurnal Pengabdian Kepada Masyarakat (JPKM) Langit Biru, 1(1), 1-6. Diambil dari http://journal.ppicurug.ac.id/index.php/jpkm/article/view/368

Dewi, G. K., Yani, I. F., Yohana, Kalbuana, N., \& Tho'in, M. (2021). Pengaruh GCG, Leverage, Pengungkapan CSR terhadap Performance Financial pada Perbankan Syariah di Indonesia dengan Ukuran Perusahaan sebagai Variabel Moderasi | Dewi | Jurnal Ilmiah Ekonomi Islam. Jurnal Ilmiah Ekonomi Islam, 7(3). Diambil dari https://jurnal.stieaas.ac.id/index.php/jei/article/view/3600

Direktorat Jenderal Perhubungan Udara. (2015). KP 39 Tahun 2015 tentang Standar Teknis dan Operasi Peraturan Keselamatan Sipil - Bagian 139 (Manual Of Standard CASR - Part 139) Volume 1 Bandar Udara (Aerodromes). I.

Direktorat Jenderal Perhubungan Udara. (2016). SKEP/ 140/ VI/ 1999 Tentang Persyaratan Dan Prosedur Pengoperasian Kendaraan Di Sisi Udara. In Laboratorium Penelitian dan Pengembangan FARMAKA TROPIS Fakultas Farmasi Universitas Mualawarman, Samarinda, Kalimantan Timur.

Haris, F. M., Rosmayanti, L., Darjono, W., Purwaningtyas, D. A., \& Sugih, E. (2021). EAST VFR Route Design at Airnav Indonesia Banjarmasin Branch Office. International Journal of Progressive Sciences and Technologies (IJPSAT), 30(1), 557-566.

Hastomo, W., Karno, A. S. B., Kalbuana, N., Nisfiani, E., \& ETP, L. (2021). Optimasi Deep Learning untuk Prediksi Saham di Masa Pandemi Covid-19. JEPIN (Jurnal Edukasi dan Penelitian Informatika), 7(2), 133-140. Diambil dari https://jurnal.untan.ac.id/index.php/jepin/article/view/47411

Hendriarto, P., Mursidi, A., Kalbuana, N., Aini, N., \& Aslan, A. (2021). Understanding the Implications of Research Skills Development Framework for Indonesian Academic Outcomes Improvement. Jurnal Iqra': Kajian Ilmu Pendidikan, 6(2), 51-60. https://doi.org/10.25217/JI.V6I2.1405

Jatmoko, D., Rosmayanti, L., Praptiningsih, N., Putriekapuja, R. A., Amir, E., Vebriyan, I. W., 


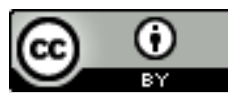

\& Azizah, N. R. (2022). Pengenalan Pemanduan Lalu Lintas Penerbangan (Air Traffic Control) Di Indonesia. Pengmasku, 2(1), 21-28. https://doi.org/10.54957/PENGMASKU.V2I1.126

Kalbuana, N; Christelia, S; Kurnianto, B; Purwanti, T; Tho'in, M. (2021). Pengaruh Ukuran Perusahaan, Leverage dan Nilai Perusahaan Terhadap Tax Avoidance Kasus Perusahaan Yang Terdaftar Di Jakarta Islamic Index (JII). Jurnal Ilmu Manajemen dan Akuntansi Terapan (JIMAT), 12(2), 190-202. Diambil dari http://jurnal.stietotalwin.ac.id/index.php/jimat/article/view/340/258

Kalbuana, Nawang; Budi R, A.Nugroho; Yulistiani, N. (2020). Pengaruh Intellectual Capital, Tata Kelola Perusahaan Dan Kualitas Audit Terhadap Manajemen Laba. JABI (Jurnal Akuntansi Berkelanjutan Indonesia), 3(1), 56-71. Diambil dari http://www.openjournal.unpam.ac.id/index.php/JABI/article/view/3830

Kalbuana, N, Prasetyo, B., Asih, P., Arnas, Y., Simbolon, S. L., Abdusshomad, A., ... Mahdi, F. M. (2021). Earnings Management Is Affected By Firm Size, Leverage And Roa: Evidence From Indonesia. Academy of Strategic Management Journal, 20(SpecialIssue2), 1-12. Diambil dari https://www.scopus.com/inward/record.uri?eid=2-s2.085107756548\&partnerID=40\&md5=f648ed22972be531e4986f7c43a47ad4

Kalbuana, Nawang, Asih, P., Putri, I. A. J., Cahyadi, C. I., Praptiningsih, N., Kadarusman, ... Rusdiyanto. (2021). Factors Affecting The Interest In Using E-Wallet Among Indonesian Millenials. Academy of Entrepreneurship Journal, 27(5), 1-10. Diambil dari https://www.abacademies.org/special-issues/volume-27-special-issue-5-titleentrepreneurship-and-economics.html

Kalbuana, Nawang, Asih, P., Simbolon, S. L., Solihin, \& Kurniawati, Z. (2021). Impact of Covid-19 Vaccination on Airline Business in Indonesia. Academy of Accounting and Financial Studies Journal, 25(3), 1-10. Diambil dari https://www.abacademies.org/journals/academy-of-accounting-and-financial-studiesjournal-inpress.html

Kalbuana, Nawang, Hendra, O., Aswia, P. R., Lestary, D., Kardi, \& Solihin. (2021). Pengenalan Unit Penanggulangan Keadaan Darurat Di Bandara Bagi Siswa SMK Penerbangan di Wilayah Lampung dan Sidoarjo. Jubaedah : Jurnal Pengabdian dan Edukasi Sekolah, 1(3), 232-239.

Kalbuana, Nawang, Sutadipraja, M. W., Purwanti, T., \& Santoso, D. (2019). Pengaruh Profitabilitas, Leverage, Kinerja Lingkungan Terhadap Pengungkapan Islamic Social Reporting (Studi Empiris pada Perusahaan yang Terdaftar di JII Tahun 2013-2017). AKTSAR: Jurnal Akuntansi Syariah, 2(2), 233-248. Diambil dari https://journal.iainkudus.ac.id/index.php/aktsar/article/view/6037

Kalbuana, Nawang, Utami, S., \& Pratama, A. (2020). Pengaruh Pengungkapan Corporate Social Responsibility, Persistensi Laba dan Pertumbuhan Laba Terhadap Manajemen Laba Pada Perusaaan Yang Terdaftar di Jakarta Islamic Index. Jurnal Ilmiah Ekonomi Islam, 6(2), 350-358. https://doi.org/10.29040/JIEI.V6I2.1107

Kementerian Perhubungan Republik Indonesia. (2015). KP 14 Tahun 2015 Standar Teknis dan Operasi Peraturan Keselamatan Penerbangan Sipil Bagian 139 (Manual of Standard CASR Part 139) Volume IV Pelayanan Pertolongan Kecelakaan Penerbangan dan Pemadam Kebakaran (PKP-PK).

Menteri Perhubungan Republik Indonesia. (2015). Peraturan Menteri Perhubungan Republik Indonesia No 127 Tahun 2015 Tentang Program Keamanan Penerbangan Nasional. In Menteri Perhubungan Republik Indonesia.

Nurwati, N., Prastio, P., \& Kalbuana, N. (2021). Influence of Firms Size, Exchange Rate, Profitability and Tax Burden On Transfer Pricing. International Journal of Economics, 
Business and Accounting https://doi.org/10.29040/IJEBAR.V5I3.2882

Research

(IJEBAR), $5(3)$.

Prasetyo, B; Utami, S; Abdusshomad, A; Wijaya, M; Kalbuana, N. (2021). Effect Of Company Value, Leverage, And Company Size On Profit Persistence In Jakarta Islamic Index (JII) Listed Companies. International Journal of Economics, Business and Accounting Research (IJEBAR), 5(1), 128-136. Diambil dari https://jurnal.stieaas.ac.id/index.php/IJEBAR/article/view/2164/1010

Prasetyo, B., Rohman, T., Solihin, S., Sundoro, S., \& Kalbuana, N. (2021). Sosialisasi Kawasan Keselamatan Operasi Penerbangan (KKOP). Jurnal Pengabdian Kepada Masyarakat (JPKM) Langit Biru, 2(1), 31-38. https://doi.org/10.54147/JPKM.V2I01.451

Presiden Republik Indonesia. (2009). Undang-Undang Republik Indonesia Nomor 1 Tahun 2009 tentang Penerbangan (hal. 109). hal. 109.

Sihono, S., Fatkhulloh, A., Saputro, R., Herwanto, D., \& Kalbuana, N. (2021). Pendalaman Buku Ajar Elektrikal dan Elektronika Pesawat Udara Bagi Guru SMK Penerbangan. Jurnal Pengabdian Kepada Masyarakat (JPKM) Langit Biru, 2(1), 46-54. https://doi.org/10.54147/jpkm.v2i01.462

Sihono, S., Fatkulloh, A., Saputro, R., Herwanto, D., Kalbuana, N., \& Kurnianto, B. (2021). Pemantapan Dan Refreshing Materi Electrical \& Electronik Untuk Guru Smk Penerbangan Di Jawa Tengah Dan Sekitarnya. Jubaedah : Jurnal Pengabdian dan Edukasi Sekolah (Indonesian Journal of Community Services and School Education), 1(1), 12-19. https://doi.org/10.46306/jub.v1i1.2

Toni, Wildan, M., Purnomo, S., Wahyudi, J., \& Fatra, O. (2022). Pelatihan Elektronika Dasar Guna Membuka Peluang Kewirausahaan Warga Desa Rancagong Kecamatan Legok $\begin{array}{llll}\text { Kabupaten } & \text { Tangerang. } & \text { Pengmasku, } & \text { 2(1), }\end{array}$ https://doi.org/https://doi.org/10.54957/pengmasku.v2i1.125

Vinod, B. (2021). The Evolution of Yield Management in the Airline Industry. https://doi.org/10.1007/978-3-030-70424-7

Yohana; Kalbuana, N; Solihin; Yanti, D. R. (2020). The Influence Of Capital Intensity, Firm Size, And Leverage On Tax Avoidance On Companies Registered In Jakarta Islamic Index (Jii) Period 2015-2019. International Journal of Economics, Business and Accounting Research (IJEBAR), 4(03). Diambil dari http://www.jurnal.stieaas.ac.id/index.php/IJEBAR/article/view/1330/727

Yohana, Gaol, R. M. L., Dewi, G. K., Kalbuana, N., \& Abdusshomad, A. (2021). Pengaruh Free Cash Flow, Profitabilitas, Kualitas Audit, Leverage, Kebijakan Dividen terhadap Likuiditas Pada Perusahaan Terdaftar di Jakarta Islamic Index | Yohana | Jurnal Ilmiah Ekonomi Islam. Jurnal Ilmiah Ekonomi Islam, 7(3). Diambil dari https://jurnal.stieaas.ac.id/index.php/jei/article/view/3601/1660 